\title{
Efeito residual do calcário sob diferentes modos de incorporação antes da instalação do sistema plantio direto
}

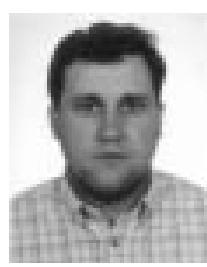

Renato de M. Prado ${ }^{1}$

1 Departamento de Solos e Adubos, FCAV/UNESP. Via de Acesso Prof. Paulo Donato Castellane, s/n. CEP 14870-000, Jaboticabal, SP. E-mail: rmprado@ fcav.unesp.br (Foto)

Protocolo 50 - 25/3/2003 - Aprovado em 29/10/2003

\begin{abstract}
Resumo: A incorporação profunda do calcário no solo na época de instalação do sistema plantio direto, pode apresentar efeito residual prolongado no perfil beneficiando as culturas. $\mathrm{O}$ objetivo deste trabalho foi testar o efeito residual do calcário sob diferentes modos de incorporação quanto à produção da soja no terceiro ano agrícola em sistema de plantio direto. Para isso, conduziu-se um experimento, utilizando um Latossolo Vermelho distrófico, textura argilosa, em Uberlândia, MG. O delineamento estatístico foi o de blocos casualizados, em parcela subdividida. Nas parcelas foram aplicados os modos de incorporação do calcário: grade aradora pesada (14 discos de 34 polegadas) e grade niveladora (60 discos de 22 polegadas); modo tradicional, com arado de disco (4 discos de 26 polegadas) e grade niveladora; grade aradora superpesada (14 discos de 34 polegadas) e grade niveladora e nas subparcelas aplicaram-se calcário dolomítico, nas doses de 0, 6,0 e $9,2 \mathrm{t} \mathrm{ha}^{-1}$. A incorporação do calcário ocorreu em maio/1995, e nos anos agrícolas subseqüentes cultivou-se a aveia-preta (1995/96) e o milho (1996/97) em sistema plantio direto. Avaliou-se, então, no ano agrícola 1997/98, o efeito residual do calcário na produção da soja. O calcário incorporado em camadas profundas na ocasião da instalação do sistema plantio direto exerceu efeito residual positivo na produção da soja. O modo de incorporação mais eficiente do calcário foi com uso da grade aradora superpesada e o menos eficiente com a grade aradora pesada.
\end{abstract}

Palavras-chave: preparo do solo, calagem, Glycine max

\section{Residual effect of lime under different types of incorporation before the installation of a no-tillage system}

\begin{abstract}
The deep incorporation of the lime at the time of installation of the no-tillage system may present a residual effect in the soil benfitial for the crops. The present work was conducted to test the residual effect of limestone incorporation on the production of the soybeans. For this purpose, an experiment was conducted on a clay textured distrophic Red Latosol, in Uberlândia, MG. A completely randomized block design in a split plot arrangement was used. The main plots were constituted by mode of incorporation of the lime: heavy disc plows (14 discs of $34 "$ ) and disc harrows (60 discs of 22"); traditional way, with disc plow (4 discs of 26") and disc harrows; superheavy disc plows (14 discs of 34") and disc harrows; in split plots, the doses of lime: $0,6.0$ and $9.2 \mathrm{t} \mathrm{ha}^{-1}$ were studied. The incorporation of the lime occurred in May/1995, and in the subsequent agricultural years black oats (1995/96) and maize (1996/97) were cultivated in notillage system. In year 1997/98, the residual effect on the production of soybeans was evaluated. The incorporated lime at the occasion of the installation of the no-tillage system had positive residual effect in the production of soybeans. The deep incorporation of the lime was more effective with use of the superheavy disc plows and the heavy disc plows revealed inefficient.
\end{abstract}

Key words: Soil management, liming, Glycine max

\section{INTRODUÇÃO}

Atualmente, admite-se a importância do plantio direto em diversas regiões produtoras de grãos do Brasil, como um sistema de produção conservacionista, que reduz as perdas de solo e de fertilizantes, incrementando a produtividade e respeitando o meio ambiente. Por outro lado, a acidez dos solos tropicais nas áreas de expansão do sistema plantio direto, constitui um dos principais fatores que, às vezes, limitam a expressão potencial produtiva das espécies cultivadas. Assim, 
a calagem é prática obrigatória para atingir alta produção das culturas, sem a necessidade de abertura de novas áreas, preservando o meio ambiente (Lopes, 1994).

Os calcários utilizados na prática da calagem em geral apresentam baixa solubilidade, necessitando de adequado contato com as partículas de solo para reagir. Portanto, sua incorporação às camadas mais profundas do solo é fundamental para a reação mais efetiva. No entanto, os agricultores negligenciam a importância desta prática, o que resulta em menor eficiência da calagem na correção da acidez do solo (Quaggio, 2000). A eficiência da calagem depende de vários fatores, com destaque para a importância da profundidade de incorporação (Andrade, 1991).

As informações sobre a eficiência de equipamentos na incorporação de corretivos em profundidades superiores a 0,20 m com homogeneidade adequada são pouco freqüentes na literatura. No Brasil, a incorporação de calcário é feita, normalmente, com grades intermediárias ou até niveladoras, o que pode resultar em reflexos negativos à qualidade física e química dos solos, tanto pela supercalagem na parte superficial como pela subcalagem nas camadas mais profundas do perfil do solo (Denardin, 1984), podendo restringir o crescimento de raízes das plantas. Paralelamente, os arados estão perdendo espaço para as grades pesadas, devido ao seu alto custo operacional (Dallmayer, 1986). Com relação à profundidade de incorporação, observa-se que as culturas anuais, em geral, apresentam respostas diferenciadas quanto à produção. A incorporação do calcário em profundidades até $0,30 \mathrm{~m}$ pode neutralizar a acidez do solo até este limite possibilitando maior desenvolvimento radicular com respostas mais positivas na produção de milho (Gonzales-Érico et al., 1979). Em áreas sob sistema plantio direto consolidado a incorporação profunda de calcário, comparada com a aplicação superficial, não possibilitou incremento de produção da soja (Sá,1993). Pesquisas envolvendo a incorporação profunda do calcário já na implantação do sistema plantio direto, para avaliação dos efeitos residuais no solo e os benefícios às culturas sucessoras devem ser estimulados. Esta justificativa fundamenta-se também na indicação de que a incorporação profunda do calcário no início da adoção do sistema plantio direto exerce efeito benéfico na produção agrícola (Prado \& Roque, 2002). A EMBRAPA (1998) recomenda a calagem para o Estado do Paraná, objetivando atingir a saturação por bases de $70 \%$, incorporando-se o calcário até a $20 \mathrm{~cm}$ de profundidade nas áreas que estão no sistema convencional e que devem passar para o sistema plantio direto.

O trabalho teve como objetivo avaliar o efeito residual do calcário sob diferentes modos de incorporação na produção da soja, no terceiro ano agrícola, sob sistema de plantio direto.

\section{MATERIAL E MÉTODOS}

O experimento foi conduzido na Fazenda Beija-Flor, no município de Uberlândia, MG. Pela classificação de Köppen, o clima do município é mesotérmico com verão quente e úmido (Cwa). O período de condução do ensaio foi de maio de 1995 a abril de 1998. O solo é um Latossolo Vermelho distrófico, que possui nas camadas de 0 a $0,20 \mathrm{~m}$ e de 0,20 a $0,30 \mathrm{~m} 410$ e $425 \mathrm{~g}_{\text {de }}$ argila $\mathrm{kg}^{-1}$, respectivamente. A área experimental vinha sendo cultivada com eucalipto por mais de 10 anos; em seguida, realizou-se cultivo com preparo convencional por meio de aração e gradagem e semeadura de arroz de sequeiro (1994/95). No ano agrícola seguinte (1995/96), aplicou-se os tratamentos de incorporação do calcário (maio de 1995) e depois cultivouse aveia preta para formação de cobertura morta no período da implantação do sistema plantio direto, conforme utilizaram Prado \& Roque (2002). No ano agrícola 1996/97, introduziu-se a cultura do milho semeado em outubro de 1996, aos 17 meses após a incorporação do calcário. No ano agrícola seguinte (1997/ 98), cultivou-se soja, objetivando avaliar o efeito residual do calcário.

Antes da aplicação do calcário e do cultivo da aveia preta (abril de 1995), foram coletadas amostras de solo das camadas de 0 a 0,$10 ; 0,10$ a 0,20 e 0,20 a $0,30 \mathrm{~m}$, para a caracterização química (Tabela 1), conforme Raij et al. (1987).

Adotou-se o delineamento experimental de blocos ao acaso, em parcelas subdivididas, com três repetições, cujos tratamentos principais, aplicados nas parcelas, foram constituídos pelos seguintes modos de incorporação do calcário: 1) metade da dose distribuída a lanço, seguido da operação com grade aradora pesada $(\mathrm{GP}+\mathrm{GN})$ com controle remoto (14 discos de 34 polegadas, espaçados $340 \mathrm{~mm}$, com peso total de $2932 \mathrm{~kg}$ e largura de corte de $2210 \mathrm{~mm}$ ), tracionada por trator de pneu 4 x 4 (Valmet $148 \times 4$ ) com $146 \mathrm{cv}$ e a outra metade, incorporada mediante a grade niveladora (60 discos de 22 polegadas); 2) metade da dose distribuída a lanço, incorporada com aração com arado de discos lisos (A+GN) (4 discos de 26 polegadas) e metade da dose também distribuída a lanço, incorporada com grade niveladora (60 discos de 22 polegadas); 3 ) dose inteira do calcário aplicado a lanço e, em seguida incorporada com grade aradora superpesada (GSP+GN), com controle remoto (14 discos de 34 polegadas), espaçados $440 \mathrm{~mm}$, com peso total de $3814 \mathrm{~kg}$ e largura de corte de $2650 \mathrm{~mm}$, tracionada por trator de esteira com $140 \mathrm{cv}$ e grade niveladora (60 discos de 22 polegadas). Nota-se que, embora as grades apresentem número e diâmetro de discos iguais, se diferenciam no peso e na distância entre discos, fatores estes que tecnicamente diferenciam as grades em pesada e superpesada e, conseqüentemente,

Tabela 1. Características químicas do Latossolo Vermelho distrófico, antes da aplicação do calcário

\begin{tabular}{|c|c|c|c|c|c|c|c|c|c|c|}
\hline \multirow{2}{*}{$\begin{array}{l}\text { Profundidade } \\
\mathrm{m}\end{array}$} & \multirow{2}{*}{$\underset{\mathrm{CaCl}_{2}}{\mathrm{pH}}$} & \multirow{2}{*}{$\begin{array}{l}\text { M.O. } \\
\mathrm{g} \mathrm{kg}^{-1}\end{array}$} & \multirow{2}{*}{$\begin{array}{c}\mathrm{P} \\
\text { (resina) } \\
\mathrm{mg} \mathrm{dm}^{-3}\end{array}$} & K & $\mathrm{Ca}$ & $\mathrm{Mg}$ & $(\mathrm{H}+\mathrm{Al})$ & SB & $\mathrm{T}$ & \multirow{2}{*}{$\begin{array}{l}\mathrm{V} \\
\%\end{array}$} \\
\hline & & & & \multicolumn{6}{|c|}{$\mathrm{mmol}_{\mathrm{c}} \mathrm{dm}^{-3}$} & \\
\hline 0 a 0,10 & 4,3 & 17 & 5 & 0,6 & 9 & 1 & 59 & 10,6 & 69,6 & 15 \\
\hline 0,10 a 0,20 & 4,1 & 16 & 3 & 0,4 & 8 & 1 & 57 & 9,4 & 66,4 & 14 \\
\hline 0,20 a 0,30 & 4,0 & 15 & 3 & 0,3 & 5 & 1 & 58 & 6,3 & 64,3 & 10 \\
\hline
\end{tabular}


quanto à profundidade de incorporação do calcário. Nas subparcelas os tratamentos secundários se constituíram de doses de calcário dolomítico (PRNT=64,0\%; RE $=87,3 \%$; $\mathrm{PN}=73,3 \% ; \mathrm{CaO}=37,2 \%$ e $\mathrm{MgO}=27,0 \%$ ), como segue: $\mathrm{D}_{0}=$ zero de calcário; $\mathrm{D}_{1}=$ dose para elevar $\mathrm{V}$ a $70 \% ; \mathrm{D}_{2}=$ dose para elevar a saturação de base (V) a $100 \%$, as quais corresponderam a 0,6,0 e 9,2 t ha-1 de calcário, respectivamente.

As parcelas experimentais foram compostas por dezesseis linhas de soja cv. Conquista (MG/BR-46), espaçadas 0,45 m entrelinhas, com densidade populacional inicial de 20 plantas por metro linear, tendo como parcela útil apenas as oito linhas centrais. As parcelas e as subparcelas apresentavam área total de 432 e $144 \mathrm{~m}^{2}$, respectivamente. A semeadura direta da soja sobre resteva da aveia preta semeada no inverno, foi realizada em 15 de novembro de 1997 e as sementes de soja foram inoculadas com estirpes selecionadas de Bradyrhizobium, em turfa, com $64 \mathrm{~g}$ de molibdato de sódio e, posteriormente, tratadas com $150 \mathrm{~g}$ de i.a. de thiram (fungicida sistêmico) para $50 \mathrm{~kg} \mathrm{de}$ sementes.

Oito meses antes do plantio da soja realizou-se uma amostragem do solo para avaliação dos efeitos dos tratamentos na neutralização da acidez do solo, com os resultados apresentados no trabalho de Prado \& Natale (2004).

A adubação de semeadura constou da aplicação de $400 \mathrm{~kg} \mathrm{ha}^{-1}$ da fórmula comercial 0-20-10 + 0,1\% Zn e, em cobertura aos 35 dias após a emergência aplicou-se, em toda área, $170 \mathrm{~kg} \mathrm{ha}^{-1} \mathrm{de}$ cloreto de potássio correspondendo a $100 \mathrm{~kg} \mathrm{~K}_{2} \mathrm{O} \mathrm{ha-1}$.

$\mathrm{Na}$ época de pleno florescimento da soja efetuou-se a leitura de altura da planta, a partir de cem plantas por parcela útil. Em 15 de abril de 1998, aos 33 meses após a incorporação do calcário, ou seja, aos 150 dias depois da semeadura, realizouse a colheita mecanizada da soja nas parcelas úteis do experimento.

Os dados foram submetidos à análise de variância. Os valores médios dos contrastes foram comparados pelo teste de Tukey $(\mathrm{P}<0,05)$ e realizado um estudo de regressão polinomial, escolhendo-se as equações significativas pelo teste F $(\mathrm{P}<0,05)$ e com maior coeficiente de determinação, empregando-se o programa SANEST-PC (Zonta et al., 1982).

\section{RESULTADOS E DISCUSSÃO}

Aos 22 meses após a incorporação do calcário (oito meses antes do plantio da soja), Prado \& Natale (2004), observaram que os efeitos benéficos do calcário no aumento da saturação por bases foram detectados até a camada de $0,10 \mathrm{~m}$, para o modo de incorporação do calcário foi a gradagem pesada; até 0,20 m, quando o calcário foi incorporado com aração e gradagem ou gradagem superpesada; e até $0,30 \mathrm{~m}$, somente com incorporação com gradagem superpesada. Assim, notase efeito diferenciado dos equipamentos agrícolas na capacidade do calcário neutralizar acidez do perfil do solo, e se espera que a soja responda diferentemente a esses níveis de acidez do perfil de solo.

Houve efeito significativo dos modos de incorporação do calcário na altura (Figura 1) e na produção de grãos de soja
(Figura 2), sendo que o modo de incorporação de calcário com grade superpesada e grade niveladora $(\mathrm{GSP}+\mathrm{GN})$, foi superior ao modo de incorporação por grade pesada $(\mathrm{GP}+\mathrm{GN})$, concordando com os resultados que tratam do efeito imediato da incorporação profunda na produção da aveia preta (Prado \& Roque, 2002) e do milho (Prado \& Natale, 2004).

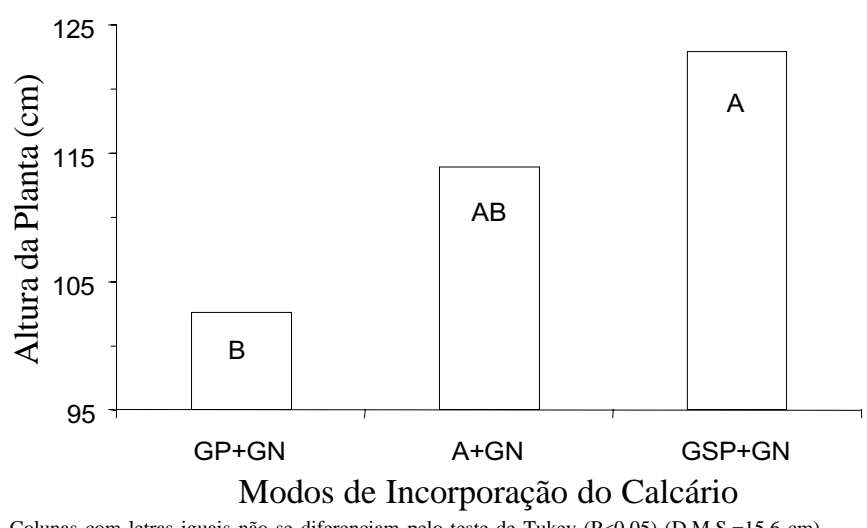

Colunas com letras iguais não se diferenciam pelo teste de Tukey (P $<0,05)$ (D.M.S. $=15,6 \mathrm{~cm}$ )
Figura 1. Altura média de plantas de soja em função dos modos de incorporação de calcário, com grade pesada e grade niveladora $(\mathrm{GP}+\mathrm{GN})$; aração e grade niveladora $(\mathrm{A}+\mathrm{GN})$ e grade superpesada e grade niveladora $(\mathrm{GSP}+\mathrm{GN})$

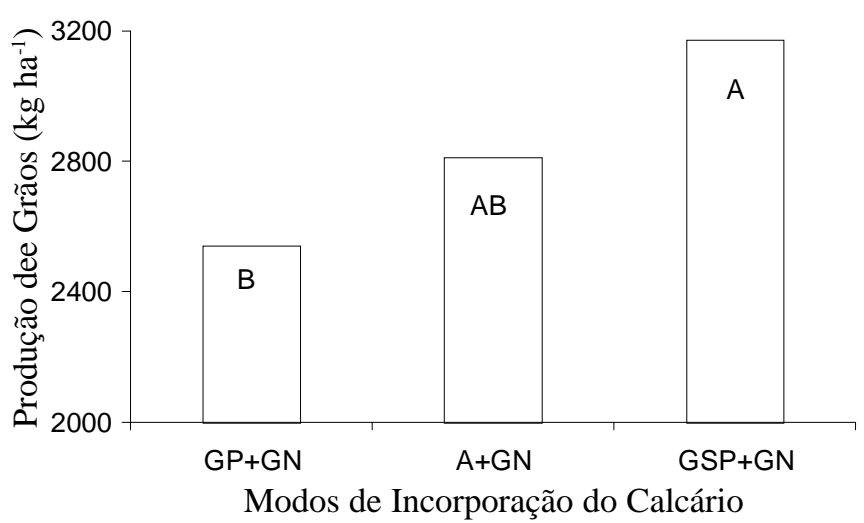

Colunas com letras iguais não se diferenciam pelo teste de Tukey $(\mathrm{P}<0,05)$ (D.M.S. $\left.=371,0 \mathrm{~kg} \mathrm{ha}^{-1}\right)$ Figura 2. Produção de grãos de soja em função dos modos de incorporação de calcário, com grade pesada e grade niveladora $(\mathrm{GP}+\mathrm{GN})$; aração e grade niveladora $(\mathrm{A}+\mathrm{GN})$; grade superpesada e grade niveladora $(\mathrm{GSP}+\mathrm{GN})$

O método convencional foi semelhante ao da gradagem pesada (Figuras 1 e 2), o que está de acordo com Oliveira et al. (1996) e Weirich Neto et al. (2000), que observaram terem sido essas duas formas de incorporação semelhantes na produção de milho. Por outro lado, discorda dos dados apresentados por Gonzales-Érico et al. (1979) e Alonso \& Ferreira (1992) que concluíram ser a prática de incorporação convencional do calcário pela aração, seguida de gradagem, superior ao da gradagem pesada. A divergência entre os autores quanto ao modo convencional e o da gradagem, na produção de milho, pode ser devida, em parte, ao grau de acidez subsuperficial, à tolerância da cultivar à acidez do solo, além da dosagem e das características do corretivo usado, com diferentes granulometrias e tempo de reação. 
Como modo opcional de incorporação do calcário, a grade superpesada se mostrou promissora quanto aos efeitos na produção da soja, pois poderia substituir o modo convencional por apenas uma operação.

A superioridade da grade superpesada em relação aos demais tratamentos se deve à maior profundidade de atuação dos benefícios da calagem. Além disso o movimento de rotação dos discos nas grades é superior ao arado, promovendo um maior contato do calcário com uma maior massa de solo e, conseqüientemente, maior velocidade de reação desse corretivo.

Por outro lado, a incorporação do calcário com grade aradora pesada mostrou-se ineficiente, resultando em baixo rendimento de grãos de soja. Esta baixa eficiência da grade aradora, segundo Denardin (1984) se deve aos reflexos negativos na qualidade física e química dos solos, ao excesso de calcário na camada superficial e à falta deste na camada mais profunda do perfil do solo, causando diminuição no crescimento das raízes das plantas e, na produção.

Para cada tonelada de calcário aplicado, a altura média das plantas de soja aumentou 3,9; 6,0 e 8,2 cm (Figura 3) e a produção de grãos aumentou 105, 162 e $238 \mathrm{~kg} \mathrm{ha}^{-1}$ (Figura 4), respectivamente, para incorporação com grade pesada, arado de disco e grade superpesada. Este efeito da calagem na produção da soja foi linear, sendo que a produção máxima esteve associada à maior dose de corretivo, empregada, 9,3 t ha ${ }^{-1}$ de calcário, ou seja, a dose calculada para elevar o valor de V a $100 \%$.

Os resultados mostram, portanto, a resposta positiva da cultura da soja à correção da acidez do solo antes da implantação do sistema plantio direto. Esse comportamento foi registrado também por Sá (1993) em experimentos conduzidos no Sul (Carambeí, PR), em Latossolo Vermelho distrófico e por Prado (1999) na região do Cerrado (Uberaba, MG) em Latossolo Vermelho distrófico, em área que recebeu aplicação de calcário antes da adoção do plantio direto. Outros autores não observaram resposta da cultura da soja à calagem depois do estabelecimento do sistema plantio direto, quando utilizaram cv. Embrapa 59, cultivada em Latossolo Vermelho-Escuro (pH

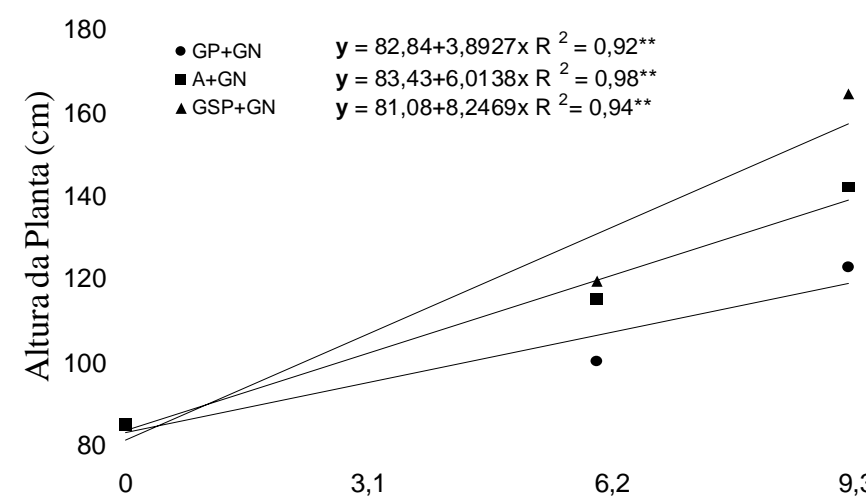

Dose de Calcário Aplicado $\left(\mathrm{t} \mathrm{ha}^{-1}\right)$

** Resultado significativo pelo teste $\mathrm{F}(\mathrm{P}<0,01)$

Figura 3. Efeitos de doses e modos de incorporação de calcário com grade pesada e grade niveladora $(\mathrm{GP}+\mathrm{GN})$; aração e grade niveladora $(\mathrm{A}+\mathrm{GN})$; grade superpesada e grade niveladora (GSP+GN) na altura média de plantas de soja em um Latossolo Vermelho distrófico

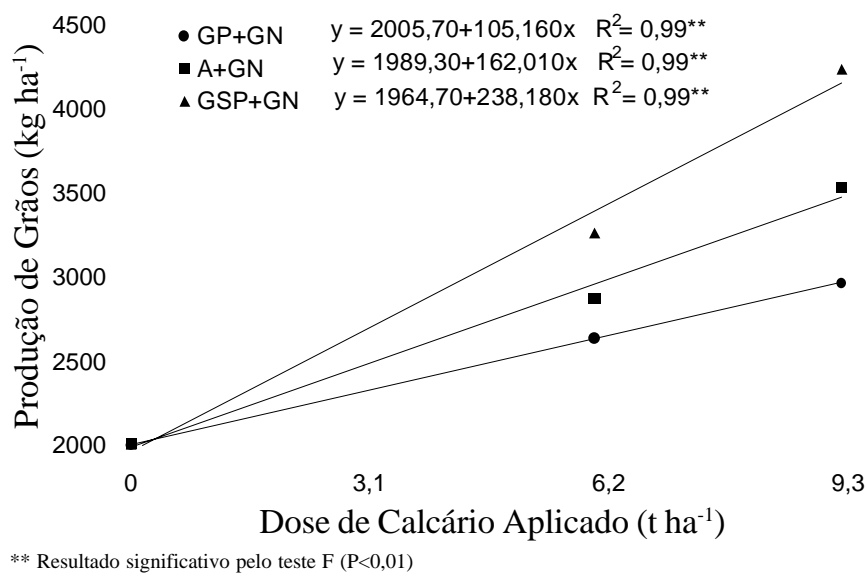

Figura 4. Efeitos de doses e modos de incorporação de calcário com grade pesada e grade niveladora $(\mathrm{GP}+\mathrm{GN})$; aração e grade niveladora $(\mathrm{A}+\mathrm{GN})$; grade superpesada e grade niveladora (GSP+GN) na produção de grãos de soja, em um Latossolo Vermelho distrófico

em $\mathrm{CaCl}_{2}$ 4,8-5,1, $\mathrm{Ca}=28-47$ e $\mathrm{Mg}=18-26 \mathrm{mmoL}_{\mathrm{c}} \mathrm{dm}^{-3}$ ) (Moreira et al., 2001). As diferenças encontradas na literatura podem ser atribuídas às condições edafoclimáticas das áreas experimentais e, sobretudo, ao uso de cultivares distintas.

Assim, Prado (2001) indica, em sistema plantio direto no cerrado, a necessidade do uso de materiais genéticos específicos para cada nível de acidez do solo. Nesse sentido, Pipolo (1999) verificou em nove genótipos de soja, variabilidade na tolerância à acidez do solo. A ausência na literatura de respostas das culturas à calagem, observada em sistema plantio direto, pode ser devido aos teores de $\mathrm{Ca}, \mathrm{Mg}$ e $\mathrm{K}$ estarem em níveis adequados no solo, apresentando uma relação adequada com o $\mathrm{Al}^{3+}$ trocável (Caires et al., 1998).

Destaca-se a correlação significativa obtida entre a altura média das plantas de soja e a produção de grãos $\left(r=0,97^{* *}\right)$, também verificada por Hoggard et al. (1978). Entretanto, o aumento da altura da planta tem efeitos positivos na produção da soja, desde que se mantenha a mesma população de plantas por área (Uben Filho \& Souza, 1993).

\section{CONCLUSÕES}

1. O calcário incorporado em camadas profundas do solo, na ocasião da instalação do sistema plantio direto, exerceu efeito residual positivo na produção da soja.

2. O modo de aplicação mais eficiente do calcário foi com uso da grade aradora superpesada e o menos eficiente com a grade aradora pesada.

\section{LITERATURA CITADA}

Alonso, A.S.; Ferreira, O.O. Incorporação profunda de fertilizantes e calcário: sua influência na produção de milho (Zea mays L.) sob estresse hídrico e, sobre algumas propriedades físicas e químicas de um solo de cerrado. In: Congresso Brasileiro de Engenharia Agrícola, 20, Londrina, 1991. Anais... Londrina: Instituto Agronômico do Paraná, 1992.p.57. 
Andrade, L.A.B. Calagem para a cultura da cana-de-açúcar. Informativo Agropecuário, Belo Horizonte, v.15,p.15-16, 1991.

Caires, E.F.; Madruga, E.F.; Chueiri, W.A.; Figueiredo, A. Alterações das características químicas do solo e resposta da soja ao calcário e gesso aplicados na superfície em sistema de cultivo sem preparo do solo. Revista Brasileira de Ciências do Solo, Viçosa, v.22,p.27-34, 1998.

Dallmeyer, A.V. As máquinas utilizadas na distribuição e incorporação de calcário. In: Simpósio sobre Aplicação de Calcário na Agricultura, 1., Campinas, 1986. Anais... Campinas: Fundação Cargill, 1986. p.23-29.

Dedecek, R.A.; Pereira, J.; Ike, M.; Iwata, F. Efeito de profundidade de aração inicial, modos de adubação corretiva e sistemas de preparo do solo na produção de soja em solo de cerrados. Revista Brasileira de Ciências do Solo, Campinas, v.10,p.173-180, 1986.

Denardin, J.E. Manejo adequado do solo para áreas motomecanizadas. In: Simpósio de Manejo do Solo e Plantio Direto no Sul do Brasil, 1, Passo Fundo, 1983. Anais... Passo Fundo: EMBRAPA, 1984. p.107-123.

EMBRAPA - Centro Nacional de Pesquisa de Soja. Reunião de Pesquisa de Soja da Região Central do Brasil, 20, Ata e Resumos. Londrina, 1998, 462p.

Gonzales-Érico, E.; Kamprath, E.J.; Narderman Jr., G.C.; Soares, W.V. Effect of depth of lime incorporation on the growth of corn on an Oxisol of Central Brazil. Soil Science Society America Journal, Madison, v.43, p.1155-1158, 1979.

Hoggard, A.L.; Shannon, J.G.; Johnson, D.R. Effect of plant population on yield and height characteristics in determinate soybeans. Agronomy Journal, Madison, v.70, p.1070-1072, 1978.

Lopes, A.S. Uso de tecnologia moderna na preservação do meio ambiente. In: Simpósio Nacional do Setor de Fertilizantes, 1, São Paulo, 1997, Anais... São Paulo: ANDA, IBRAFOS, 1994. p.247-280.

Moreira, S.G.; Kiehl, J.C.; Prochnow, L.I.; Pauletti, V. Calagem em sistema de semeadura direta e efeitos sobre a acidez do solo, disponibilidade de nutrientes e produtividade de milho e soja. Revista Brasileira de Ciências do Solo, Viçosa, v.25, p.71-81, 2001.
Oliveira, I.P.; Kluthcouski, J.; Yokoyama, L.P.; Dutra, L.G.; Portes, T.A.; Silva, A.E.; Pinheiro, B.S.; Ferreira, E.; Castro, E.M. Sistema Barreirão: recuperação/ Renovação de pastagens degradadas em consórcio com culturas anuais. Goiânia, Empresa Brasileira de Pesquisa Agropecuária, 1996. 90p. EMBRAPA-CNPAF. Documentos, 64

Pipolo, A.E. Eficiência e resposta de cultivares de soja à calagem e à adubação fosfatada. In: Congresso Brasileiro de Soja, 1. Londrina. Anais... Londrina: EMPRAPA Soja, 1999. p.424.

Pöttker, D.; Ben, J.R. Calagem para uma rotação de culturas no sistema de plantio direto. Revista Brasileira de Ciências do Solo, Viçosa, v.22, p.675-684, 1998.

Prado, R.M. Influência da saturação de bases na implantação do sistema plantio direto em solo de cerrado. Efeito na produção da cultura da soja. Revista de Agricultura, v.74, n.3, p.269-277, 1999.

Prado, R.M. Saturação por bases e híbridos de milho sob sistema plantio direto. Scientia Agricola, Piracicaba, v.58, p.391-394, 2001.

Prado, R.M; Natale, W. Uso da grade aradora superpesada, pesada e arado de disco na incorporação de calcário em profundidade e na produção do milho. Engenharia Agrícola, Jaboticabal, v.24, n.1, 2004. [prelo]

Prado, R.M.; Roque, C.G. Uso alternativo da grade aradora superpesada na correção da acidez do solo em profundidade e na produção da aveia preta. Revista Brasileira de Ciências do Solo, Viçosa, v.26, p.275-281, 2002.

Quaggio, J.A. A acidez e calagem em solos tropicais. Campinas, Instituto Agronômico de Campinas, 2000. 111p.

Raij, B.van; Quaggio, J.A.; Cantarella, H. Análise química do solo para fins de fertilidade. Campinas: Fundação Cargill, 1987. 107p.

Sá, J.C.M. Manejo da fertilidade do solo no sistema de plantio direto. In: Plantio direto no Brasil. Passo Fundo: Ed. Aldeia Norte, 1993. p.37-59.

Urben Filho, G.; Souza, P.I.M. Manejo da cultura da soja sob cerrado: época, densidade e profundidade de semeadura. In: Arantes, N.E.; Souza, P.I.M. (eds.) Cultura da soja nos cerrados. Piracicaba: POTAFOS, p.267-298,1993.

Weirich Neto, P.H.; Caires, E.F.; Justino, A.; Dias, J. Correção da acidez do solo em função de modos de incorporação de calcário. Ciências Rural, Santa Maria, v.30, p.257-261, 2000.

Zonta, E.P.; Machado, A.A.; Silveira JR., P. Sistema de análise estatística - SANEST. Pelotas, 1982. Registro SEI no 066060 